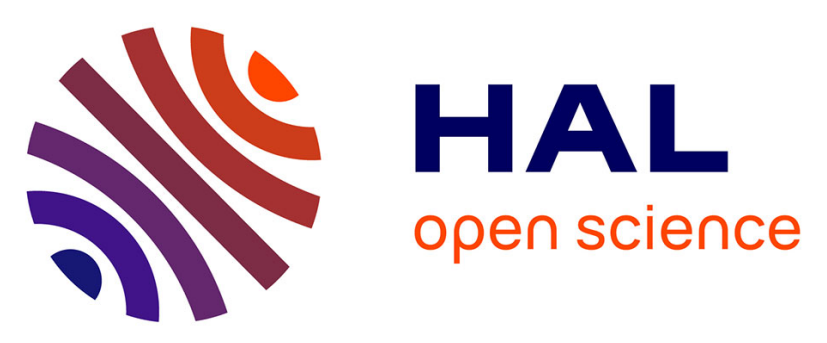

\title{
Gemcitabine as second-line chemotherapy after Folfirinox failure in advanced pancreatic adenocarcinoma: A retrospective study
}

Juliette Viaud, Clémence Brac, Pascal Artru, Estelle Le Pabic, Bérengère Leconte, Anaïs Bodere, Marc Pracht, Samuel Le Sourd, Julien Edeline, Astrid Lièvre

\section{To cite this version:}

Juliette Viaud, Clémence Brac, Pascal Artru, Estelle Le Pabic, Bérengère Leconte, et al.. Gemcitabine as second-line chemotherapy after Folfirinox failure in advanced pancreatic adenocarcinoma: A retrospective study. Digestive and Liver Disease, 2017, 49 (6), pp.692-696. 10.1016/j.dld.2017.02.007 . hal-01534249

HAL Id: hal-01534249

https://hal-univ-rennes1.archives-ouvertes.fr/hal-01534249

Submitted on 4 Jul 2017

HAL is a multi-disciplinary open access archive for the deposit and dissemination of scientific research documents, whether they are published or not. The documents may come from teaching and research institutions in France or abroad, or from public or private research centers.
L'archive ouverte pluridisciplinaire HAL, est destinée au dépôt et à la diffusion de documents scientifiques de niveau recherche, publiés ou non, émanant des établissements d'enseignement et de recherche français ou étrangers, des laboratoires publics ou privés. 


\title{
Gemcitabine as second-line chemotherapy after Folfirinox failure in advanced pancreatic adenocarcinoma: a retrospective study
}

\author{
Juliette Viaud ${ }^{1}$, Clémence Brac ${ }^{2}$, Pascal Artrư ${ }^{3}$, Estelle Le Pabic ${ }^{4}$, Bérengère
}

Leconte $^{1}$, Anaïs Bodère ${ }^{1}$, Marc Pracht ${ }^{2}$, Samuel Le Sourd ${ }^{2}$, Julien Edeline ${ }^{5}$ and Astrid Lièvre ${ }^{6}$

1 CHU Rennes, Service des maladies de l'Appareil Digestif, Rennes, France

2 Département d’Oncologie Médicale, Centre Eugene Marquis, Rennes, France.

3 Département d’hépatogastroentérologie et oncologie digestive, Hôpital Jean Mermoz, Lyon, France

4 CHU Rennes, Service de Pharmacologie Clinique, Rennes, France; Université Rennes 1, CIC Inserm 1414,

Rennes, France

5 Département d’Oncologie Médicale, Centre Eugene Marquis, Rennes, France; Université Rennes 1, Faculté de médecine, Rennes, France

6 CHU Rennes, Service des maladies de l'Appareil Digestif, Rennes, France; Université Rennes 1, Faculté de médecine, Rennes, France

Electronic Word Count: 2377

Corresponding author : Astrid Lièvre

Service des maladies de l'appareil digestif, CHU Pontchaillou ,2 rue Henri Le Guilloux, 35033

Rennes Cedex 09

Mail : astrid.lievre@chu-rennes.fr 


\begin{abstract}
Background: Pancreatic adenocarcinoma (PA) is diagnosed in most cases at an advanced stage requiring chemotherapy. Folfirinox is the standard first-line treatment. After Folfirinox failure, gemcitabine alone is routinely used as second-line therapy without data supporting this attitude.
\end{abstract}

Aim: Determine the response rate and outcome of patients with advanced PA treated with gemcitabine after Folfirinox failure.

Methods: We retrospectively analyzed all consecutive patients treated with gemcitabine after Folfirinox failure for a locally advanced or metastatic PA between 2009 and 2015 . Progression-free survival (PFS) and overall survival (OS) were calculated using the KaplanMeier method. Response rate, control rate and tolerability were assessed.

Results: 96 patients were included (male,51\%; median age,62; performance status (PS) 0-1, 47\%). Median duration on gemcitabine was 2.1 months. The overall disease control rate was 40\%. Median OS was 3.7 months (95\% Cl: 2.5-5.2) and median PFS was 2.1 months $(95 \% \mathrm{Cl}$ : 2.0-2.6). Reasons for treatment discontinuation were mostly progression (51\%). Age at diagnosis and PS were independently associated with OS in multivariate analysis (HR of 1.86; $p=0.0055$ and 2.42; $p<0.0001$ respectively). 34 patients experienced a grade 3 adverse event. Conclusions: This study suggests that gemcitabine is not beneficial to all patients failing on Folfirinox first-line therapy and should be restricted to young patients with good PS. 
Keywords: Advanced pancreatic cancer, Folfirinox, gemcitabine, second-line chemotherapy

\section{Background}

Pancreatic adenocarcinoma is a frequent malignancy worldwide ${ }^{1}$ associated with a five-year overall survival (OS) rate between $5 \%$ and $7 \%$ in USA and Europe respectively ${ }^{2,3}$. At the time of diagnosis, most patients present with a locally advanced or metastatic disease precluding surgical resection. For these patients, survival without any treatment is less than 5 months ${ }^{4}$ and palliative chemotherapy is the only therapeutic option, associated with median OS

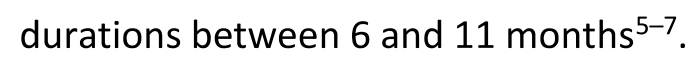

Current standards in first-line treatment of fit patients with an advanced disease are Folfirinox and nab-paclitaxel plus gemcitabine regimens, both having shown their superiority over gemcitabine alone in two phase III studies ${ }^{5,6}$. Until recently, after progression during first-line therapy, there was no standard second-line treatment although literature suggests that an increasing number of patients ( 40 to $60 \%$ ) would be able to receive a second-line therapy ${ }^{5,6,8}$.

Only one phase III study from the German CONKO-study group compared a second-line chemotherapy including fluorouracil, folinic acid and oxaliplatin to best supportive care (BSC) in this setting and showed an improvement of second-line OS (4.8 vs 2.3 months; $\mathrm{p}=0.031$ ) without major toxicities but failed by insufficient accrual ${ }^{9}$. The same regimen significantly improved OS and PFS when compared to fluorouracil/ folinic acid alone in another phase III study from the same group that included 168 gemcitabine-refractory patients ( 5.9 vs 3.3 months, $p=0.01$ and 2.9 vs 2.0 months, $p=0.019$ respectively $)^{10}$. These 
results suggested the interest of an oxaliplatin-based second-line therapy but were not confirmed by the Canadian PANCREOX trial who compared modified FOLFOX6 and infusional FU/leucovorin and found no difference in PFS (3.1 vs 2.9 months, $p=0.99)$ and inferior OS in patients assigned to mFOLFOX6 (6.1 vs 9.9 months, $p=0.02)^{11}$. Recently, nanoliposomal irinotecan in combination with fluorouracil/ folinic acid has shown a significant improvement of median OS (6.1 vs 4.2 months), progression-free survival (PFS) and objective response rate over fluorouracil/ folinic acid alone in the NAPOLI-1 phase III study ${ }^{12}$. Other studies have reported median OS between 3 and 9 months, suggesting a benefit of chemotherapy compared to BSC and a meta-analysis of 34 studies confirmed this impression by showing a survival benefit of 3.2 months $(p=0.013)$ in patients treated compared to those who only received $\mathrm{BSC}^{13}$. However, most of these studies have been performed before the era of Folfirinox and nab-paclitaxel-gemcitabine in patients progressing on gemcitabine alone.

Since the publication of the study by Conroy et al., Folfirinox has become the reference regimen in Europe and USA for the first-line treatment of advanced pancreatic cancer patients with a good performance status (PS) and a level of bilirubin $\leq 1.5$ ULN ${ }^{14,15}$. After failure on Folfirinox, a gemcitabine-based chemotherapy is recommended according to ASCO and ESMO clinical practice guidelines but with a low level of evidence ${ }^{14,15}$ as poor data are available in this setting ${ }^{16-19}$.

The aim of this retrospective multicenter study was to determine the response rate and outcome of patients with advanced pancreatic adenocarcinoma treated with gemcitabine alone as second-line treatment after failure on Folfirinox and to identify prognostic factors in this setting.

\section{Methods}




\section{Patients}

All consecutive patients with a histological proven metastatic or locally advanced pancreatic adenocarcinoma treated with gemcitabine after Folfirinox failure between October 2009 and December 2015 in 3 centers (Rennes University Hospital, Eugène Marquis Cancer Center and Jean Mermoz private hospital) were retrospectively enrolled.

Medical records of patients were reviewed to collect relevant data on demographics, tumor characteristics, pancreatic surgery, adjuvant gemcitabine chemotherapy, biliary stenting, pancreatic radiation, Eastern Cooperative Oncology Group (ECOG) PS and serum levels of carbohydrate antigen 19-9 (CA 19-9) before the start of second-line chemotherapy. The following first-line Folfirinox characteristics were collected: number of cycles, best response (RECIST v1.1) and reasons for treatment cessation.

\section{Second-line treatment and outcome measures}

Each cycle of gemcitabine consisted of a 30 min intravenous infusion of gemcitabine at a dose of $1000 \mathrm{mg}$ per $\mathrm{m}^{2}$ on days 1,8 , and 15 every 4 weeks. This regimen was delivered until disease progression, unacceptable toxicity or patient refusal.

The following data regarding second-line-gemcitabine were collected: date of first and last infusions, number of cycles, potential dose reductions and their reasons, and reasons for treatment cessation.

Tolerability was assessed by analyzing all chemotherapy-related adverse events reported during the second-line treatment and if specified, their grade according to the National Cancer Institute Common Terminology Criteria for Adverse Events (NCI-CTCAE) V4.0.

Tumor response was assessed in patients with measurable disease every 2 months by chestabdomen-pelvis by means of computed tomography or magnetic resonance imaging according to the RECIST version 1.1 criteria $^{20}$. 
Any third-line chemotherapy administered after disease progression was also recorded. After progression, all patients were followed up until death.

\section{Statistical analysis}

Quantitative variables were expressed as medians and range. Categorical variables were presented as counts and percent of the cohort.

PFS was calculated from the date of gemcitabine initiation to the date of disease progression or death, whichever came first. Surviving patients without disease progression were censored at the date of last follow up. OS was calculated from the date of gemcitabine initiation to death. Surviving patients were censored at the date of last follow up.

PFS and OS curves were estimated by the Kaplan Meier method. For univariate and multivariate analysis, Cox's proportional hazards model was used to calculate hazard ratios (HR) with 95\% confidence intervals (Cl) for PFS and OS. All tests were two-sided and p-value $<0.05$ was considered to be statistically significant.

This study was approved by the Rennes University Hospital Ethics Committee for all participating centers.

\section{Results}

\section{Patient and tumor characteristics}

Among a total of 206 patients treated between October 2009 and December 2015 by Folfirinox in first-line, 96 (47\%) patients received gemcitabine alone in second-line. Baseline characteristics of study population are depicted in Table 1 . The median age of patients was 62 years and $51 \%$ of them were male. Most tumors were located in the head of pancreas and most patients had a metastatic disease, preferentially located in the liver. A total of 12 patients (13\%) had previously undergone a pancreatic surgery, including 6 who received 
gemcitabine as adjuvant chemotherapy. Patients have received Folfirinox in first-line for a median duration of 5.9 months and $64 \%$ of them were treated for more than 4 months, with an objective response rate of $40 \%$.

Of note, prior to second-line chemotherapy, only $47 \%$ of patients had a PS of $0-1$. Most patients showed an elevated CA19-9 serum level (> $400 \mathrm{UI} / \mathrm{ml}$ ) among the 65 patients in whom this data was available. Gemcitabine was usually started because of disease progression $(84 \%$, table 1$)$.

\section{Toxicity}

Median duration on gemcitabine was 2.1 months (range $0.2-15.8$ ). Patients received a median number of 2 cycles (range 1-14). There was no treatment-related death. A total of 34 patients experienced at least one grade 3 toxicity, which was mainly hematologic and/or asthenia. Toxicities are described in Table $\mathbf{2}$.

A total of 23 patients (24\%) required a dose reduction, mainly due to asthenia (14 patients, $61 \%$ ) or hematologic toxicities (9 patients, 39\%). Chemotherapy was adjourned at least one time in 30 patients (31\%).

\section{Tumor response and Survival}

The tumor response was assessable in 80 patients with measurable disease. There was no complete response. 8 patients achieved a partial response (10\%) and $24(30 \%)$ a stable disease. The overall disease control rate was $40 \%$ (Table 3 ).

After a median follow-up of 10.9 months (1.2-51) since the beginning of Folfirinox and 3.7 months (0.2-19.7) since the beginning of gemcitabine, the median OS from the start of second-line therapy was 3.7 months $(95 \% \mathrm{Cl}: 2.5-5.2)$. The 6-months and 12 -months OS rates were $35 \%(95 \% \mathrm{Cl}: 26.2-45.8)$ and $10 \%(95 \% \mathrm{Cl}: 5.4-19.4)$ respectively (Figure 1$)$. The median PFS from the start of second-line therapy was 2.1 months (95\% Cl:2.0-2.6). The 6-months and 
12-months PFS rates were $16 \%(95 \% \mathrm{Cl}: 10.2-25.8)$ and $2 \%(95 \% \mathrm{Cl}: 0.6-8.5)$ respectively

(Figure 2). The median OS from the start of first-line chemotherapy was 11.2 months (95\%Cl:10.4-14.0). The 12-months and 24-months OS rates were $46 \%(95 \% \mathrm{Cl}: 36.6-57)$ and $13 \%$ (95\% $\mathrm{Cl}: 7.6-22.6)$ respectively.

Reasons for gemcitabine discontinuation were disease progression $(n=49,51 \%)$, side effects $(n=15,16 \%)$, patient death $(n=24,25 \%)$ and patient preference $(n=5 ; 5 \%) .3$ patients were still on treatment at the end of the follow up and 33 patients (34\%) received a third-line therapy.

\section{Prognostic factors}

In univariate analysis, age at diagnosis [ $>62$ years versus $\leq 62$ years; $H R=1.05,95 \% \mathrm{Cl}$ : 0.68 1.63; $p=0.0049]$ and ECOG-PS score [ $>1$ versus $\leq 1 ; \mathrm{HR}=2.40,95 \% \mathrm{Cl}: 1.56-3.71 ; p<0.0001]$ were the only factors significantly associated with OS in these patients treated with gemcitabine second-line therapy. Sex, tumor stage, number of metastatic sites, CA 19-9 level and even response to first-line chemotherapy were not associated with OS.

In multivariate analysis, age at diagnosis and ECOG-PS were still significantly and independently associated with OS with a HR of $1.86(95 \% \mathrm{Cl}: 1.20-2.88 ; \mathrm{p}=0.0055)$ and 2.42 (95\%Cl: $1.56-3.75 ; p<0.0001)$ respectively (Table 4). OS was thus 6.48 months $(95 \% \mathrm{Cl}: 4.18-$ 9.86) among PS 0-1 patients and 2.47 months (95\% Cl: $1.68-2.79)$ among PS $2-3$ patients.

We also evaluated the association between these factors and the PFS. In univariate analysis, ECOG-PS score ( $>1$ versus $\leq 1 ; \mathrm{HR}=1.77,95 \% \mathrm{Cl}: 1.17-2.67 ; p=0.0069)$ and CA 19.9 level $(>400$ versus $\leq 400 ; \mathrm{HR}=2.06,95 \% \mathrm{Cl}: 1.12-3.80 ; \mathrm{p}=0.0205)$ were the only factors associated with PFS, of which, only ECOG-PS was still independently associated with PFS in multivariate analysis with a HR of $2.39(95 \% \mathrm{Cl}: 1.42-4.03 ; \mathrm{p}=0.0011)$. PFS was thus 2.66 months 
(95\% Cl:2.04-4.07) among PS 0-1 patients and 1.84 months $(95 \% \mathrm{Cl}: 1.28-2.27)$ among PS $2-3$ patients.

\section{Discussion}

Folfirinox has become the treatment of choice in first-line treatment of fit patients with metastatic pancreatic adenocarcinoma ${ }^{5,14,15}$. Despite the increasing use of this regimen, there is a lack of data regarding second-line therapy and no consensus second-line treatment after Folfirinox failure in patients with good $\mathrm{PS}^{14,15}$. However, gemcitabine is routinely used in this setting, based on its efficacy in first line of advanced pancreatic cancer where this molecule was for 15 years the standard treatment ${ }^{21}$.

This study provides results about gemcitabine efficacy as second-line chemotherapy after Folfirinox failure. To our knowledge, it represents the largest reported experience with gemcitabine alone after Folfirinox failure in the literature. Median second-line OS and PFS were relatively short ( 3.7 and 2.1 months respectively), particularly compared to the median OS of 5.6 months found in first line with this drug in the pivotal study of Burris et al. ${ }^{21}$, and were generally lower than those reported in first studies evaluating other second-line chemotherapy regimen after gemcitabine failure (OS: 3.3 to 6.6 months; PFS 2.0 to 5.0 months $)^{8-11}$. This retrospective study reflects routine practices as no selection has been made among patients receiving gemcitabine as second-line treatment, with $25 \%$ of patients older than 70 years and $53 \%$ of them with an ECOG-PS score of 2 or 3 before starting treatment. This high proportion of old and/or frail patients in our study could explain the poor results of gemcitabine we found.

Some previous studies investigated second-line chemotherapy regimen after Folfirinox failure and often found better survival rates than ours. A phase II study of the AGEO group 
evaluated the combination of nab-paclitaxel plus gemcitabine in 57 patients and found median OS and PFS of 8.8 and 5.1 months respectively ${ }^{16}$. In the same way, Zhang et al. found median OS and PFS of 5.3 and 2.7 months respectively in a small series of 28 patients treated with the same combination ${ }^{17}$. Better patient outcomes reported in these studies might be explained by the superiority of nab-paclitaxel plus gemcitabine over gemcitabine alone demonstrated in first-line ${ }^{6}$. Moreover, patients included in these studies were younger and had a better PS than our patients (79\% and $96 \%$ of patients with PS 0-1 respectively).

Two other studies found similar results than ours. An Italian study investigated 40 patients who received second-line single agent (gemcitabine, docetaxel, nab-paclitaxel) or doublets (gemcitabine with either nab-paclitaxel, capecitabine, cisplatin or docetaxel) after Folfirinox failure. The exact number of patients that received gemcitabine alone was unknown but median PFS and OS of all patients were 2.7 and 3.4 months respectively, without significant difference between single agents and doublets ${ }^{18}$. Finally, a small Portuguese study investigated gemcitabine alone after Folfirinox failure in 20 patients and found median PFS and OS of 2.0 and 5.7 months respectively. To our knowledge, this is the only other published study investigating gemcitabine alone after Folfirinox failure but it included very few patients and most of them had still a good PS ${ }^{19}$.

As shown in others studies, we observed that ECOG-PS score was an independent prognostic factor. PS 0-1 patients had a longer OS than PS 2-3 patients. Previous studies had already shown the prognostic value of this parameter in other cancers, including advanced biliary tract cancers 22,23 . The other independent prognostic factor associated with better outcomes in our study was a young age. Young people are supposed to benefit most from chemotherapy than elders even if we lack of data regarding elderly. In most studies reported above, patients were less than 75 years and multivariate analysis was not significant for this 
parameter. We did not find any other prognostic factor, particularly, response to gemcitabine was not influenced by prior response to Folfirinox. One lesson we could learn from the prognostic analysis is that we have to better select patients who could most benefit from second-line chemotherapy and exclude elderly and/or frail patients.

This study had several limitations: the retrospective design first, that caused a lack of data such as the CA 19-9 baseline level in 31 patients or others potential prognostic factors such as albumin concentration; the limited number of centers participating to the study and finally, the lack of selection of patients who received second-line gemcitabine, which is however a reflection of clinical routine practices.

In the future, beside chemotherapy, management of pancreatic adenocarcinoma will have to take into account new therapeutic options such as the PEGylated recombinant human hyaluronidase that showed promising results combined to nab-paclitaxel/gemcitabine in previously untreated stage IV pancreatic cancer patients ${ }^{24}$.

\section{Conclusions}

Gemcitabine alone as second-line chemotherapy after Folfirinox failure in patients treated for a pancreatic adenocarcinoma is not a satisfying option regarding to our results. Although retrospective, our study suggests that gemcitabine alone is not beneficial to all patients and that a better selection of patients, based on age and general condition is crucial. Nabpaclitaxel plus gemcitabine could be a promising option in this setting but it has to be confirmed in prospective and large trials. New drugs are needed to expect a survival improvement of these patients. In the future, since approaches targeting EGFR and angiogenesis have been disappointing, management of advanced pancreatic adenocarcinoma will have to take into account other therapeutic classes. 


\section{List of abbreviations used}

OS, overall survival - BSC, best supportive care - PFS, progression-free survival - PS, Performance Status - ECOG, Eastern Cooperative Oncology Group - CA 19-9, carbohydrate antigen 19-9 - RECIST, Response Evaluation Criteria in Solid Tumors - HR, Hazard Ratio - $\mathrm{Cl}$, Confidence Interval.

\section{Competing interests}

The authors declare that they have no competing interests.

\section{References}

1. Ferlay J, Shin H-R, Bray F, et al. Estimates of worldwide burden of cancer in 2008: GLOBOCAN 2008. Int J Cancer 2010; 127: 2893-2917

2. Siegel RL, Miller KD, Jemal A. Cancer statistics, 2016. CA Cancer J Clin 2016; 66: $7-30$

3. Lepage C, Capocaccia R, Hackl M, et al. Survival in patients with primary liver cancer, gallbladder and extrahepatic biliary tract cancer and pancreatic cancer in Europe 1999-2007: Results of EUROCARE-5. Eur J Cancer 2015;51:2169-2178

4. Hidalgo M. Pancreatic Cancer. N Engl J Med 2010; 362: 1605-1617

5. Conroy $\mathrm{T}$, Desseigne $\mathrm{F}$, Ychou $\mathrm{M}$, et al. FOLFIRINOX versus gemcitabine for metastatic pancreatic cancer. $N$ Engl J Med 2011; 364: 1817-1825

6. Von Hoff DD, Ervin T, Arena FP, et al. Increased survival in pancreatic cancer with nab-paclitaxel plus gemcitabine. N Engl J Med 2013 ; 369 : 1691-1703

7. Conroy $\mathrm{T}$, Bachet J-B, Ayav A, et al. Current standards and new innovative approaches for treatment of pancreatic cancer. Eur J Cancer 2016; 57: 10-22

8. Dahan L, Bonnetain F, Ychou M, et al. Combination 5-fluorouracil, folinic acid and cisplatin (LV5FU2-CDDP) followed by gemcitabine or the reverse sequence in metastatic pancreatic cancer: final results of a randomised strategic phase III trial (FFCD 0301). Gut 2010; 59: 1527-1534

9. Pelzer U, Schwaner I, Stieler J, et al. Best supportive care (BSC) versus oxaliplatin, folinic acid and 5-fluorouracil (OFF) plus BSC in patients for second-line advanced 
pancreatic cancer: a phase III-study from the German CONKO-study group. Eur J Cancer 2011; 47: 1676-1681

10. Oettle H, Riess H, Stieler JM, et al. Second-line oxaliplatin, folinic acid, and fluorouracil versus folinic acid and fluorouracil alone for gemcitabine-refractory pancreatic cancer: outcomes from the CONKO-003 trial. J Clin Oncol 2014; 32: 2423-2429

11. Gill S, Ko Y-J, Cripps C, et al. PANCREOX: A Randomized Phase III Study of 5Fluorouracil/Leucovorin With or Without Oxaliplatin for Second-Line Advanced Pancreatic Cancer in Patients Who Have Received Gemcitabine-Based Chemotherapy. J Clin Oncol 2016;JCO685776.

12. Wang-Gillam A, Li C-P, Bodoky G, et al. Nanoliposomal irinotecan with fluorouracil and folinic acid in metastatic pancreatic cancer after previous gemcitabine-based therapy (NAPOLI-1): a global, randomised, open-label, phase 3 trial. Lancet 2016; 387: 545-557

13. Rahma OE, Duffy A, Liewehr DJ, et al. Second-line treatment in advanced pancreatic cancer: a comprehensive analysis of published clinical trials. Ann Oncol 2013; 24: 1972-1979

14. Ducreux M, Cuhna AS, Caramella C, et al. Cancer of the pancreas: ESMO Clinical Practice Guidelines for diagnosis, treatment and follow-up. Ann Oncol 2015 ; 26: v56-v68

15. Sohal DPS, Mangu PB, Khorana AA, et al. Metastatic Pancreatic Cancer: American Society of Clinical Oncology Clinical Practice Guideline. J Clin Oncol 2016; JCO671412

16. Portal A, Pernot S, Tougeron D, et al. Nab-paclitaxel plus gemcitabine for metastatic pancreatic adenocarcinoma after Folfirinox failure: an AGEO prospective multicentre cohort. Br J Cancer 2015; 113: 989-995

17. Zhang Y, Hochster H, Stein S, et al. Gemcitabine plus nab-paclitaxel for advanced pancreatic cancer after first-line FOLFIRINOX: single institution retrospective review of efficacy and toxicity. Exp Hematol Oncol 2015;4:29

18. C. Pellei, A. Bittoni, K. Andrikoulet al. Single-agent or doublets as second-line chemotherapy after FOLFIRINOX in patients with locally advanced or metastatic pancreatic cancer, Ann Oncol 2014, 25 Suppl 4: iv201-iv253

19. da Rocha Lino A, Abrahão CM, Brandão RM, et al. Role of gemcitabine as secondline therapy after progression on FOLFIRINOX in advanced pancreatic cancer: a retrospective analysis. $J$ Gastrointest Oncol 2015; 6: 511-515

20. Therasse P, Arbuck SG, Eisenhauer EA, et al. New guidelines to evaluate the response to treatment in solid tumors. European Organization for Research and Treatment of Cancer, National Cancer Institute of the United States, National Cancer Institute of Canada. $J$ Natl Cancer Inst 2000; 92: 205-216

21. Burris HA, Moore MJ, Andersen J, et al. Improvements in survival and clinical benefit with gemcitabine as first-line therapy for patients with advanced pancreas cancer: a randomized trial. J Clin Oncol 1997; 15: 2403-2413 
22. Brieau B, Dahan L, De Rycke Y, et al. Second-line chemotherapy for advanced biliary tract cancer after failure of the gemcitabine-platinum combination: A large multicenter study by the Association des Gastro-Entérologues Oncologues. Cancer 2015; 121: 3290-3297

23. Bridgewater J, Lopes A, Wasan $\mathrm{H}$, et al. Prognostic factors for progression-free and overall survival in advanced biliary tract cancer. Ann Oncol 2016; 27: 134-140

24. Hingorani SR, Harris WP, Hendifar AE, et al. High response rate and PFS with PEGPH20 added to nab-paclitaxel/gemcitabine in stage IV previously untreated pancreatic cancer patients with high-HA tumors: Interim results of a randomized phase II study. ASCO Meet Abstr 2015; 33: 4006 


\section{Figures legends}

Figure 1 Kaplan Meier analysis of overall survival from the start of gemcitabine second-line chemotherapy

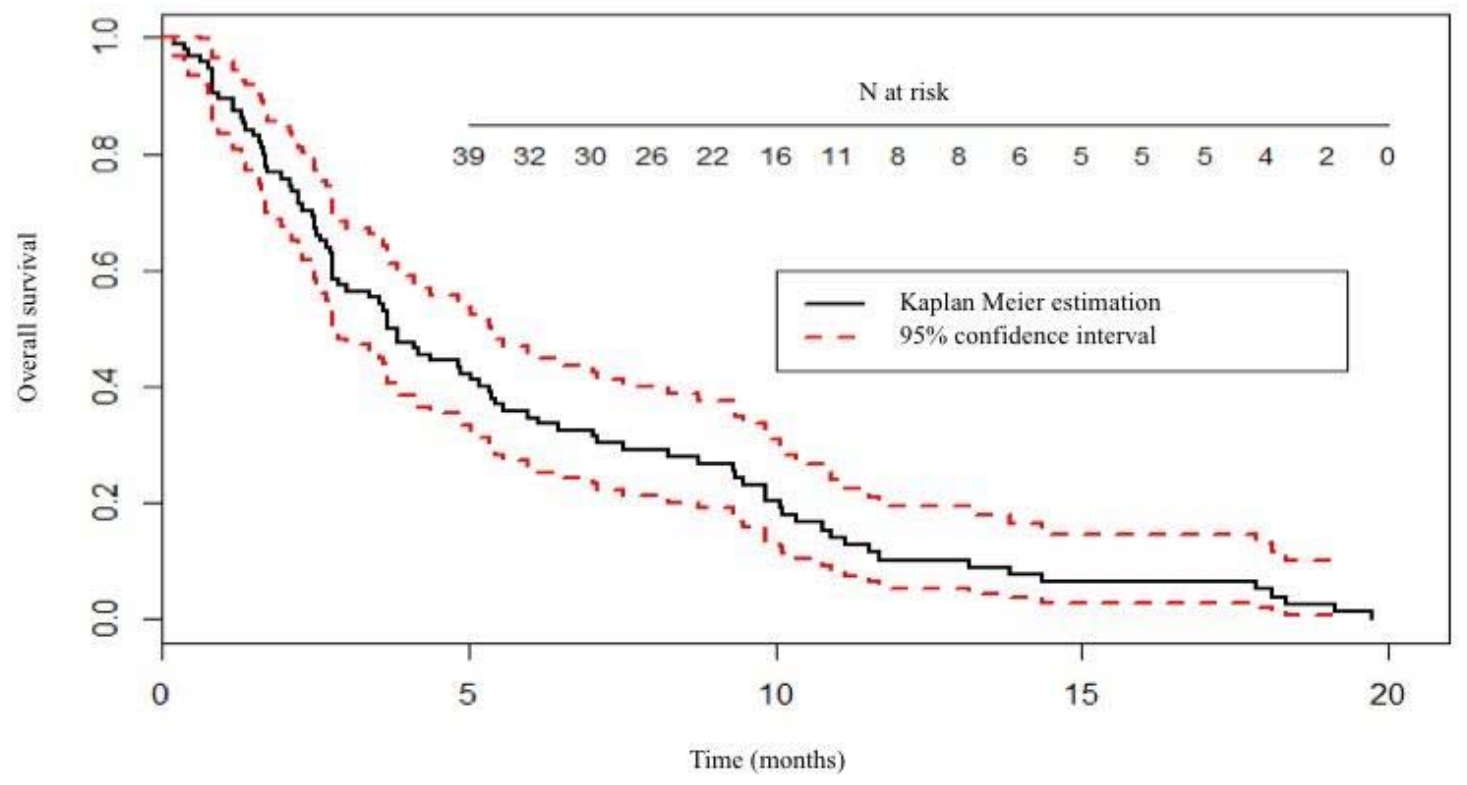


Figure 2 Kaplan Meier analysis of progression-free survival from the start of gemcitabine second-line chemotherapy

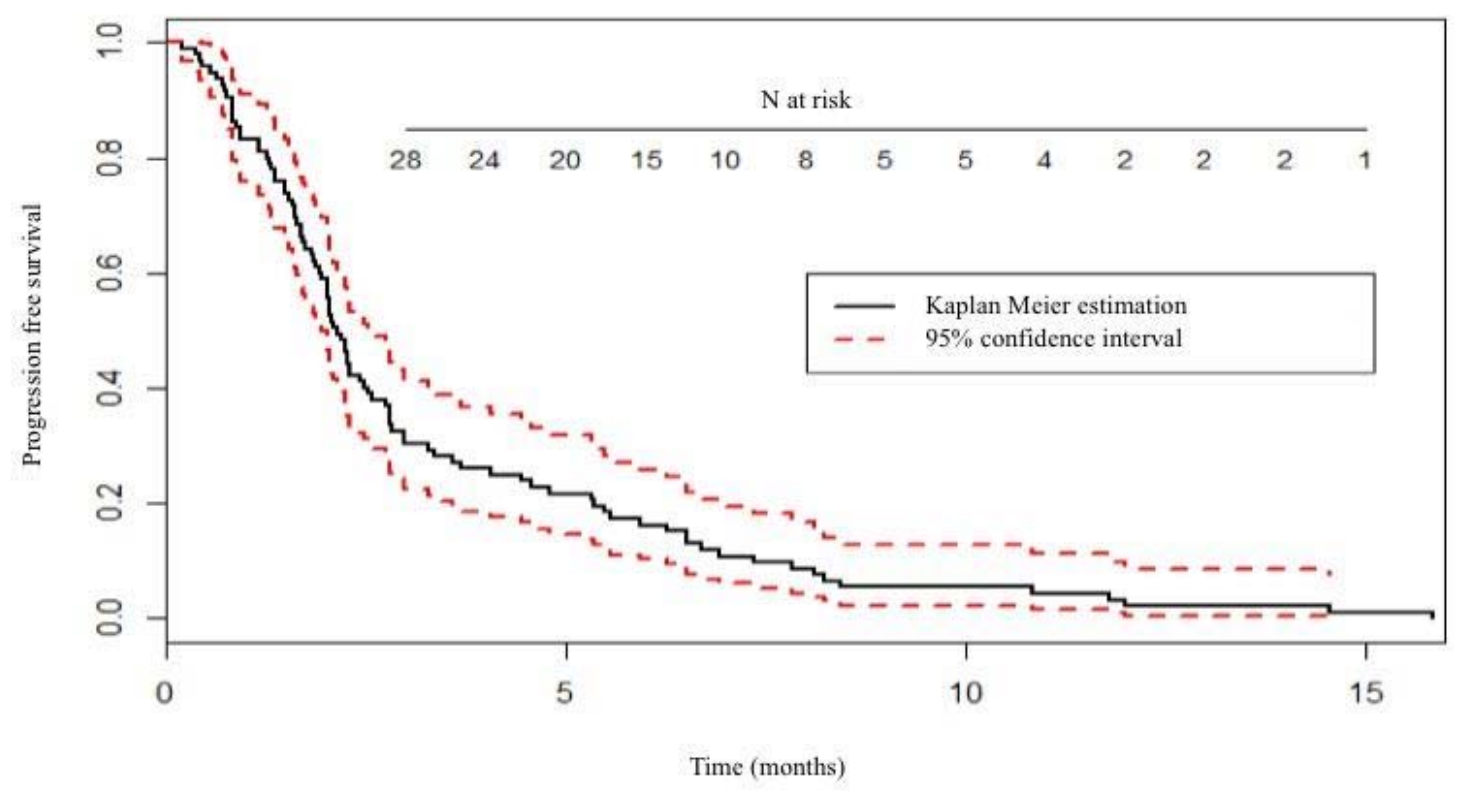


Table 1 Patient and tumor characteristics

\begin{tabular}{|c|c|}
\hline Number of patients & 96 \\
\hline Median Age [range], years & $62[38-80]$ \\
\hline \multicolumn{2}{|l|}{ Gender $\mathbf{n}(\%)$} \\
\hline Male & $49(51)$ \\
\hline Female & 47 (49) \\
\hline \multicolumn{2}{|l|}{ ECOG-PS score $n(\%)$} \\
\hline 0 & $11(12)$ \\
\hline 1 & $34(35)$ \\
\hline 2 & $45(47)$ \\
\hline 3 & $6(6)$ \\
\hline \multicolumn{2}{|l|}{ Pancreatic tumor location $\mathrm{n}(\%)$} \\
\hline Head & $44(46)$ \\
\hline Body & $31(32)$ \\
\hline Tail & $21(22)$ \\
\hline \multicolumn{2}{|l|}{ Metastatic sites $\mathrm{n}(\%)$} \\
\hline \multicolumn{2}{|l|}{ - Number of metastatic sites } \\
\hline 0 & $9(10)$ \\
\hline 1 & $57(59)$ \\
\hline$\geq 2$ & $30(31)$ \\
\hline \multicolumn{2}{|l|}{ - Location of metastasis } \\
\hline Liver & $68(71)$ \\
\hline Lung & $23(24)$ \\
\hline Peritoneum & $23(24)$ \\
\hline Other & $10(10)$ \\
\hline \multicolumn{2}{|l|}{ Baseline CA 19-9 serum level $n$ (\%) } \\
\hline$\leq 400 \mathrm{UI} / \mathrm{ml}$ & $18(19)$ \\
\hline$>400 \mathrm{UI} / \mathrm{ml}$ & $47(49)$ \\
\hline unknown & $31(32)$ \\
\hline median [range], $\mathrm{UI} / \mathrm{ml}$ & $1561(0-1233720)$ \\
\hline Biliary stent $n(\%)$ & $26(27)$ \\
\hline \multicolumn{2}{|l|}{ First line Folfirinox chemotherapy characteristics } \\
\hline - $\quad$ Number of cycles, median [range] & $7[1-24]$ \\
\hline - Duration, months, median [range] & $5.9[0.9-38]$ \\
\hline \multicolumn{2}{|l|}{ - $\quad$ Tumor response, $n(\%)$} \\
\hline complete response & $0(0)$ \\
\hline partial response & $38(40)$ \\
\hline stable disease & $28(29)$ \\
\hline progression disease & $25(26)$ \\
\hline non-evaluable & $5(5)$ \\
\hline - $\quad$ Reasons for treatment cessation, $\mathrm{n}(\%)$ & \\
\hline Progression & $81(84)$ \\
\hline Toxicity & $15(16)$ \\
\hline Prior adjuvant gemcitabine chemotherapy $\mathrm{n}(\%)$ & $6(6)$ \\
\hline
\end{tabular}


No. of patients (\%)

\begin{tabular}{llll}
\hline Grade 1 & Grade 2 & Grade 3 & Grade 4
\end{tabular}

\section{Hematologic event}

Neutropenia

$5(5)$

$8(8)$

$11(11)$

$1(1)$

Thrombocytopenia

$21(22)$

$6(6)$

$5(5)$

$1(1)$

Anemia

35 (37)

$17(18)$

$3(3)$

$0(0)$

Non hematologic event

$\begin{array}{lllll}\text { Asthenia } & 16(17) & 17(18) & 19(20) & 0(0) \\ \text { Nausea/vomiting } & 12(13) & 5(5) & 2(2) & 0(0) \\ \text { Mucitis } & 5(5) & 0(0) & 0(0) & 0(0) \\ \text { Diarrhea } & 8(8) & 0(0) & 0(0) & 0(0) \\ \text { Neurotoxicity } & 5(5) & 1(1) & 0(0) & 0(0) \\ \text { Hand Foot syndrome } & 0(0) & 0(0) & 0(0) & 0(0) \\ \text { Alopecia } & 3(3) & 0(0) & 0(0) & 0(0)\end{array}$

Toxicities were evaluated according to National Cancer Institute Common Terminology Criteria for Adverse Events (version 4.0) 
Table 3 Tumor Response to gemcitabine and Survival

Tumor response (No. of Patients) (\%)

Total of assessable patients

80

Complete response

$0(0)$

Partial Response

$8(10)$

Stable disease

$24(30)$

Progression disease

$48(60)$

Median progression free survival (months) $[95 \% \mathrm{Cl}]$

$2.1[2.0-2.6]$

Median overall survival (months) $[95 \% \mathrm{Cl}]$

$3.7[2.5-5.2]$ 
Table 4 Univariate and Multivariate analysis for overall survival

\begin{tabular}{|c|c|c|c|c|c|c|c|}
\hline \multirow[b]{2}{*}{ Variables } & \multirow[b]{2}{*}{$\mathrm{N}$} & \multicolumn{3}{|c|}{ Univariate analysis } & \multicolumn{3}{|c|}{ Multivariate analysis } \\
\hline & & $\mathrm{HR}$ & $95 \% \mathrm{Cl}$ & $p$ & $\mathrm{HR}$ & $95 \% \mathrm{Cl}$ & $p$ \\
\hline $\begin{array}{l}\text { Sex } \\
\text { (female vs male) }\end{array}$ & 96 & 1.07 & {$[0.70-1.62]$} & 0.7651 & & & \\
\hline $\begin{array}{l}\text { Age at diagnosis } \\
\text { (>62 vs } \leq 62 \text { years) }\end{array}$ & 96 & 1.05 & {$[0.68-1.63]$} & 0.0049 & 1.86 & {$[1.20-2.88]$} & 0.0055 \\
\hline $\begin{array}{l}\text { ECOG-PS score } \\
(>1 \text { vs } 0-1)\end{array}$ & 96 & 2.40 & {$[1.56-3.71]$} & $<0.0001$ & 2.42 & {$[1.56-3.75]$} & $<0.0001$ \\
\hline $\begin{array}{l}\text { Tumor Stage } \\
\text { (metastatic vs locally advanced) }\end{array}$ & 96 & 1.29 & {$[0.64-2.63]$} & 0.4787 & & & \\
\hline $\begin{array}{l}\text { Number of metastatic sites } \\
(>1 \text { vs } \leq 1)\end{array}$ & 96 & 1.08 & {$[0.68-1.71]$} & 0.7412 & & & \\
\hline $\begin{array}{l}\text { CA 19-9 level } \\
\text { (> } 400 \text { vs } \leq 400 \mathrm{Ul} / \mathrm{ml})\end{array}$ & 65 & 1.14 & {$[0.75-1.73]$} & 0.5543 & & & \\
\hline First-line response & & & & & & & \\
\hline disease control vs progression & 91 & 1.47 & {$[0.90-2.39]$} & 0.1204 & & & \\
\hline objective response vs no response & 91 & 1.21 & {$[0.78-1.87]$} & 0.3982 & & & \\
\hline $\begin{array}{l}\text { First line PFS } \\
\text { ( }>4 \text { vs } \leq 4 \text { months) }\end{array}$ & 96 & 0.79 & {$[0.51-1.23]$} & 0.2976 & & & \\
\hline
\end{tabular}

Abbreviations: HR, Hazard Ratio; 95\%Cl, 95\% confidence Interval; ECOG-PS, Eastern Cooperative Oncology Group-Performance Status; CA 19.9, Carbohydrate Antigen 19.9; PFS, Progression Free Survival. 